Article

\title{
Evaluating Social Performance of Construction Projects: An Empirical Study
}

\author{
Xiaer Xiahou ${ }^{1}$, Yuchun Tang ${ }^{1}$, Jingfeng Yuan ${ }^{1, *} \mathbb{C}$, Tengyuan Chang ${ }^{1}{ }^{(\mathbb{D})}$, Ping Liu ${ }^{1,2}$ and \\ Qiming Li ${ }^{1}$ \\ 1 Department of Construction Management and Real Estate, School of Civil Engineering, Southeast University, \\ Nanjing 211189, China; xh@seu.edu.cn (X.X.); tangyuchunseu@163.com (Y.T.); changty@seu.edu.cn (T.C.); \\ liupvip@foxmail.com (P.L.); seulqming@163.com (Q.L.) \\ 2 School of Civil Engineering, Lanzhou University of Technology, Lanzhou 730050, China \\ * Correspondence: jingfeng-yuan@seu.edu.cn; Tel.: +86-25-8379-3257
}

Received: 4 June 2018; Accepted: 4 July 2018; Published: 5 July 2018

\begin{abstract}
The concept of sustainable development is gaining increasing popularity in construction industry. Previous studies have prioritized on the sustainable performance of construction projects from perspectives of economy and environment, social performance of construction projects has not drawn much attention. Social performance of construction projects refers to the extent which the projects meet the needs of current and future generations. Therefore, social performance of construction projects is critical for project success as well as social sustainability. However, a systematic framework for evaluating social performance of construction projects is absent. At the same time, existing methods are time-consuming and subject to certain degree of subjectivity. To overcome these limitations, the fuzzy analytical hierarchy process (FAHP) method is introduced in this paper to evaluate social performance of construction projects. A real-world hospital redevelopment project was employed as an empirical study to develop the systematic framework for social performance evaluation using FAHP method. By analyzing previous studies and the hospital redevelopment project, a systematic framework with 18 indicators of five dimensions (i.e., socio-economy development, socio-environment development, social flexibility, public service development, and environment and resource conservation) was developed. Social performance of two proposed schemes for hospital redevelopment project were evaluated using the FAHP approach. Results show Scheme 2 has a relative higher social performance sore than that of Scheme 1 and the hospital redevelopment project would improve socio-economy development, socio-environment development, social flexibility, and public service development, while it brings challenges to environment and resource conservation. More seriously, results indicate the hospital project may threaten healthcare and disease prevention of the local communities. Therefore, more measures should be taken to improve social performance of the hospital redevelopment project. The empirical study shows the proposed framework using FAHP method is viable for conducting social performance evaluation of construction projects, which could be helpful to improve social performance, reduce negative social impacts, and contribute to the social sustainability of construction projects.
\end{abstract}

Keywords: social performance; social performance evaluation; fuzzy analytical hierarchy process; empirical study

\section{Introduction}

It has been recognized that construction industry plays significant roles for the sustainable development [1,2]. Activities within lifecycle of construction projects have inherent impacts (i.e., economic impacts, environmental impacts, and social impacts) to the society [3]. Compared to 
economic and environmental impacts, social impacts associated with construction projects, are the least explicit in the "triple bottom line" principle of sustainable development [4,5]. Social impacts of construction projects refer to certain social consequences to human populations of construction projects that change the ways in which people live, work, play, relate to one another, organize to meet their needs, and generally cope as members of society $[5,6]$. The development of construction projects may lead to both positive and negative social impacts, e.g., land acquisition and disposal, resettlement of nearby residents, and resource depletion $[7,8]$. Under certain conditions, social impacts could evolve into social risks and even lead to social conflicts between different stakeholders if they are not dealt with carefully and properly [9]. To mitigate negative social impacts, social impact assessment (SIA) has widely been used within lifecycle of construction projects [10,11]. International Association for Impact Assessment (IAIA) defines social impact assessment (SIA) as processes of analyzing, monitoring and managing the intended and unintended social consequences, both positive and negative, of planned interventions (policies, programs, plans, and projects) and any social change processes invoked by these interventions [12]. Instead of addressing social performance of the project, the primary goal of SIA is to ensure the sustainability and equity of biophysical and human environment $[13,14]$.

Social performance refers to an organization's response to anticipated or existing social demands $[15,16]$. As a project-oriented industry, the major goal of construction firms/organizations is to provide the society with varieties of construction projects, social performance of construction projects could be aggregated to the construction firms/organizations level and the industry level [17]. Therefore, social performance of construction projects is crucial for the social sustainability, which is to meet the demands of current and future populations and communities $[14,18]$, and improving social performance has been a major concern by all stakeholders $[5,19]$. Previous studies have measured economic and environmental performance of construction projects, while social performance, as a critical and indispensable dimension for project success and sustainable development $[20,21]$, has not been well studied [21-23]. It is vital to study the social performance of construction projects and evaluate social performance of construction projects, which would not only help the decision makers to make decisions when proposing a construction project but also enable the project managers to audit a project and determine what kind of future improvements could be made [24].

Social performance evaluation of construction projects could be defined as improving social performance by providing information about achievement of social aspects, it allows decision makers to determine its ongoing performance in meeting social criteria, which helps reduce social impacts, prevent social risks, improve the overall performance of the project, and finally contribute to social sustainability $[15,25]$. While various studies have discussed the SIA of construction projects $[7,8,26]$, social performance evaluation of construction projects are rarely studied. Yuan [20] studied the social performance of construction waste management, which emphasized the management process of construction waste and the introduced research approach could not be transferred to evaluate social performance of construction projects. A previous study conducted by Shen, et al. [2] presented a checklist for evaluating sustainability performance, indicators reflecting social sustainability performance of construction projects were listed as reference for conducting further evaluation. Prior studies indicate that the research gap exists in social performance evaluation of construction projects.

This research developed a systematic framework for social performance evaluation of construction projects. A hospital redevelopment project was introduced as the empirical study. In addition, this study could also help to understand social performance of construction projects. The remainder of this article is as follows: Section 2 illustrates research background and the literature review. Detailed processes of FAHP-based method to evaluate social performance of construction projects are described in Section 3. A systematic framework for social evaluation is developed in Section 4 by analyzing prior studies and the introduced hospital redevelopment project. An empirical study of social performance of two proposed schemes for the hospital redevelopment project are evaluated using the developed approach, which is presented in Section 5. Results of the empirical study are discussed in Section 6. Finally, research findings and limitations are stated. 


\section{Research Background and Literature Review}

\subsection{Social Performance of Construction Projects}

Social performance of construction projects reflects the extent to which the lifecycle of construction projects meets the demands of anticipated or existing social demands. Therefore, social performance of construction projects could be obtained by analyzing social impacts of construction projects and the requirements for social sustainability by diverse stakeholders. Shen, et al. [2] explored the indicators for social sustainability performance evaluation of different stages. Valdes-Vasquez, et al. [14] identified 50 processes for social sustainability consideration during planning and design phase of construction projects, and these processes were categorized into six categories, namely stakeholder engagement, user considerations, team formation, management considerations, impact assessment, and place context. Zuo, et al. [27] interviewed domain experts and 26 criteria of social sustainability were identified, which were further discussed from three dimensions, i.e., macro level, external stakeholders, and internal stakeholders. Tilt, et al. [7] applied SIA to explore social impacts in a large dam project. These impacts are identified as migration and resettlement of people near the dam sites, changes in the rural economy and employment structure, effects on infrastructure and housing, impacts on non-material or cultural aspects of life, and impacts on community health and gender relations. Almahmoud, et al. [28] studied social core functions (SCFs) of a construction project from perspectives of diverse stakeholders. Capital performance, health and physical comfort, accessibility, integration, usability psychological comfort, and operation health and safety were identified as SCFs of a construction project. Li, et al. [8] studied social impacts of an affordable housing project and indicators reflecting social impacts were discussed from three aspects as socio-economic effects, adaptabilities, and social risks. Wang, et al. [5], Shi, et al. [9], Liu, et al. [19], and Liu, et al. [29] also addressed the social risks of the construction projects. They suggested that the projects should not only be compliant with the regulations but also meet the requirements of diverse stakeholders, especially the end-users, which will improve project social flexibility and thereby contribute to project social sustainability.

\subsection{Performance Management and Evaluation}

Performance management, which is defined as a closed loop control system that deploys policy and strategy, and obtains feedback from various levels to manage the performance of the system [30], has been widely adopted by a wide range of industries [31,32]. Performance management could help the project managers to continuously improve its project management practices [33]. Construction industry is no exception to the gaining popularity of performance management. Several construction firms have adopted performance management to enhance the performance of construction industry at different levels, e.g., organization level, stakeholders level, and project level [31,32]. As a project-oriented industry, the performance of construction projects is crucial to project success as well as the satisfaction of the organization and diverse stakeholders [34]. However, there are diverse goals of construction projects; accordingly, construction projects performance management should also cover a wide range of themes, e.g., quality, cost, time, safety and health, environment, and client satisfaction [34-37]. Traditionally, the management of construction performance relied on three indicators (i.e., cost, time, and quality), which are lagging and fails to provide a holistic view [24]. Construction projects, e.g., infrastructure projects, are complex engineering systems, which require tremendous investment and would have profound and long-time impacts on the economy, environment, and society [38]. As opined by Atkinson [39], apart from "The Iron Triangle", more success criteria should be accepted in project management. There are increasing studies investigating on the social aspects of construction projects from diverse perspectives including safety and health $[34,40]$, social impacts, social risks, social conflicts $[7,9,19,34]$, etc. Social performance has been perceived as critical aspects for sustainable development and project success.

Performance evaluation is the process of determining the efficiency and/or effectiveness of past action, which has been widely adopted to measure the performance of construction projects [34]. 
Several frameworks were proposed to help the evaluation of construction projects performance. Among the proposed performance evaluation frameworks, three are the most prevalent in construction industry: European Foundation for Quality Management (EFQM) Excellence Model, Balanced Scorecard (BSC), and Key performance indicators (KPIs) model [32]. EFQM Excellence Model is a quality-based framework [31], which is frequently and more appropriately applied at the organizational level [32,41]. BSC framework consists of a range of "leading and lagging" indicators and the scorecard is divided into four perspectives, namely financial, custom, internal business, and innovation learning [31,34]. Different perspectives interact under certain principles [31]. Even though the BSC is more prevalent in performance management at project-level, four perspectives are far from enough to cover the performance of construction projects, and more perspectives should be supplemented to measure the performance of construction projects. KPI framework, which adopts the method of benchmarking, selects time, cost, quality, client satisfaction, change orders, business performance, and health and safety as the seven key performance indicators to measure the performance of construction projects. In practice, KPI framework is more flexible, indicators of different aspects could be clustered to measure certain aspects of project performance, which makes it widely adopted in construction projects performance measurement, and various studies have been conducted to measure the overall or partial performance of construction projects [34,42]. Based on KPI framework, several tools have been developed to help the evaluation of construction projects social performance such as SIA tool [12], checklist method [2], success factors identification, social network analysis [28], etc. However, current calculation methods for social performance management based on KPI framework are subjected to certain degree of objective [32]. Alternative approaches should be devised to reduce this limitation.

To sum up, performance management has been employed to help project managers continuously improve project outcomes, social performance as one of the key aspects for projects success and sustainability is gaining increasing interests by research scholars and practitioners. Unfortunately, social performance of construction projects has not been systematically studied. In addition, among three most prevalent performance measurement frameworks for performance management in construction industry, KPI framework based on benchmarking method is the most appreciated for developing tools to evaluate construction project social performance. However, since indicators for social performance are intangible, KPI-based approach is time-consuming in identifying indicators and relatively subjective. Therefore, considerations should be given to mitigate the subjectivity of these tools.

\section{The FAHP-Based Method for Social Performance Evaluation}

To improve the efficiency and reduce the degree of subjectivity, the fuzzy analytical hierarchy process (FAHP) was adopted in this study to develop the approach for the evaluation of construction projects social performance. The method of FAHP is developed from AHP method, which was first established by Saaty [43] in 1981. The AHP method has been widely used by scholars in many fields, including performance measurement [32]. However, the application of AHP method is yield to the degree of uncertainty and subjectivity. Zeng, et al. [44] pointed that experts may find it hard to select a single number in the comparison process. Instead of a definite value, it would be proper to give a range values for comparison, e.g., 2 to 5. To avoid the deficiency, FAHP approach proposed by Zeng, et al. [44] was employed in this research to conduct social performance evaluation. The FAHP approach consists of the following six successive steps.

\section{Step 1: Identification of attributes}

In the first step, the FAHP is adopted to identify the common attributes of the given problem. A comprehensive and accurate identification of these attributes is fundamental for the evaluation approach, as the study relies heavily on these attributes while the misconception of these attributes results in a failure of the research model. Similarly, as depicted by Bititci, et al. [30], performance measurement is usually determined by the metric of a number of indicators, and thereby the 
fundamental step would be the identification of indicators that could be employed to evaluate social performance of construction projects.

Step 2: Pairwise comparisons under fuzzy environment

Once the attributes related to the problem were clearly identified, a pairwise comparison among the common attributes has to be made: one over and another under the fuzzy environment. To set up this fuzzy pairwise comparison, experts are invited to complete a comparative questionnaire. Answers from experts are used to compare each attribute and convert the linguistic comparison into the fuzzy pairwise relation matrix.

$$
\widetilde{A}=\left[\begin{array}{ccccc}
1 & \widetilde{r_{12}} & \widetilde{r_{13}} & \cdots & \widetilde{r_{1 n}} \\
\widetilde{r_{21}} & 1 & \widetilde{r_{23}} & \cdots & \widetilde{r_{2 n}} \\
\vdots & \vdots & \vdots & \ddots & \vdots \\
\widetilde{r_{n 1}} & \widetilde{r_{n 2}} & \cdots & \cdots & 1
\end{array}\right]
$$

Step 3: Defuzzification

The pairwise comparison was composed of fuzzy numbers in Step 2, and then these triangular fuzzy numbers are transformed into crisp numbers. The conversation process is called defuzzification process. For various types of defuzzification methods are buried in the literatures, this study utilizes the centroid method of defuzzification for its wide acceptance [45]. The linguistic variables described by fuzzy numbers are denoted by membership functions [45], which are presented in Table 1 and Figure 1, separately.

Table 1. Scale for relative importance used in the pairwise comparison matrix.

\begin{tabular}{ccccc}
\hline $\begin{array}{c}\text { Intensity of } \\
\text { Importance }\end{array}$ & Fuzzy Number & Linguistic Variables & $\begin{array}{c}\text { Triangular Fuzzy } \\
\text { Numbers (TFNs) }\end{array}$ & $\begin{array}{c}\text { Reciprocal of } \\
\text { TFNs }\end{array}$ \\
\hline 1 & $\widetilde{1}$ & Equally important & $(1,1,3)$ & $(1 / 3,1,1)$ \\
3 & $\widetilde{3}$ & Weakly important & $(1,3,5)$ & $(1 / 5,1 / 3,1)$ \\
5 & $\widetilde{5}$ & Important & $(3,5,7)$ & $(1 / 7,1 / 5,1 / 3)$ \\
7 & $\widetilde{7}$ & Strongly important & $(5,7,9)$ & $(1 / 9,1 / 7,1 / 5)$ \\
9 & $\widetilde{9}$ & Extremely important & $(7,9,11)$ & $(1 / 11,1 / 9,1 / 7)$ \\
\hline
\end{tabular}

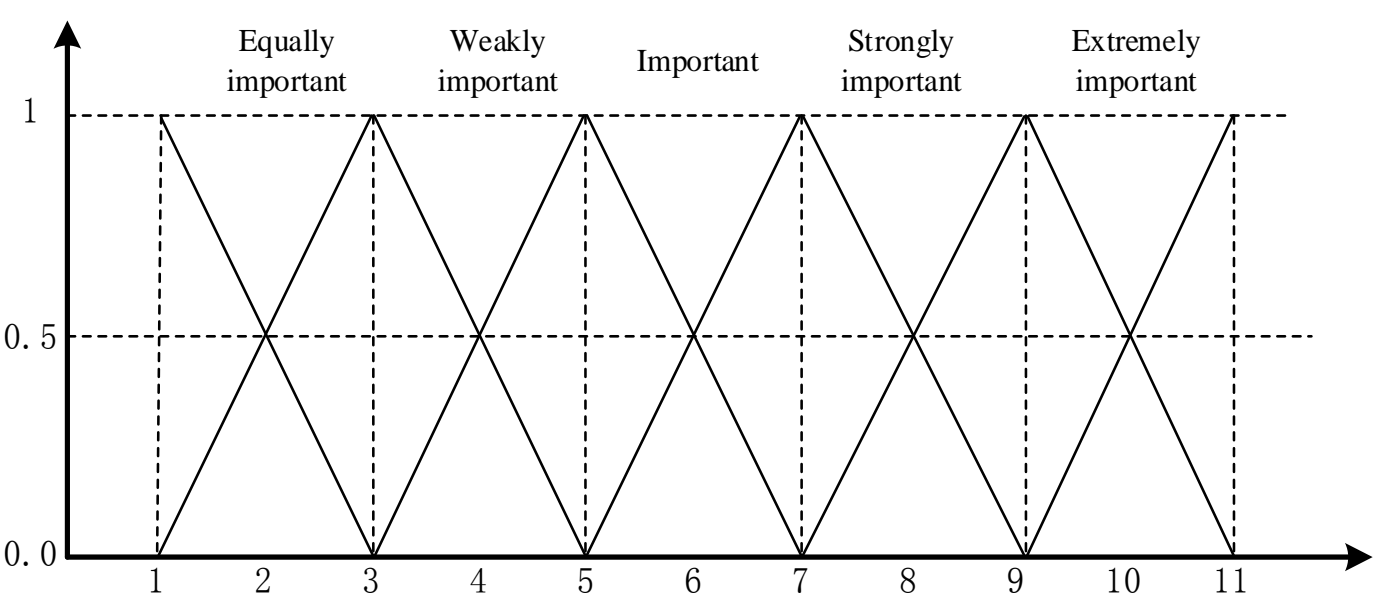

Figure 1. Fuzzy membership function for linguistic expressions for criteria. 
Step 4: Estimation of global weights

The defuzzified pairwise comparison gained from the previous steps is processed through various standard arithmetic operations of formal AHP to seek the global weights of each attribute $(W)$. The calculations processes standardize the defuzzified pairwise comparison matrix (all values in the matrix should be kept between 0 and 1 ) and calculate the eigenvalue (x) with the help of the sum of standardized rows, where the eigenvalue is the global weight of each attribute $(W)$ [46].

Step 5: Consistency check

The collected data based on the experts' judgements are subject to a certain degree of subjectivity, which naturally has errors. Therefore, the consistency of these attributes of the criteria and the relevant steps should be checked. The consistency index (CI) introduced for a pairwise comparison matrix is listed below:

$$
C I=\frac{\lambda_{\max }-n}{n-1}
$$

where $\lambda_{\max }$ is the largest eigenvalue of the comparison matrix; and $n$ is the dimension of the matrix or the number of decision criteria under consideration.

The consistency ratio $(C R)$ is given as:

$$
C R=\frac{C I}{R I(n)}
$$

where $R I(n)$ is a random index relying on the size of matrix. The random index values of random matrices introduced are listed in Table 2. If the consistency ratio $(C R)$ is equal to or less than 0.1 , the result is acceptable. However, if the value is greater than 0.1 , the decision makers have to remake pairwise comparisons to achieve consistency in their responses.

Table 2. Random index values.

\begin{tabular}{ccccccccccc}
\hline $\mathbf{N}$ & $\mathbf{1}$ & $\mathbf{2}$ & $\mathbf{3}$ & $\mathbf{4}$ & $\mathbf{5}$ & $\mathbf{6}$ & $\mathbf{7}$ & $\mathbf{8}$ & $\mathbf{9}$ & $\mathbf{1 0}$ \\
\hline $\mathrm{RI}(\mathrm{n})$ & 0 & 0 & 0.58 & 0.90 & 1.12 & 1.24 & 1.32 & 1.41 & 1.45 & 1.51 \\
\hline
\end{tabular}

Step 6: Establishment of assessment sets and fuzzy comprehensive assessment of multiple indices

Fuzzy comprehensive assessment method can be used to quantify the fuzzy indices or define the membership degree via building hierarchical fuzzy subsets, which is based on the fuzzy transformation to synthesize each index.

To quantify different attributes of each assessment index, the semantic scales of subjective assessments are used to establish assessment classes, namely, $V=\left(v_{1}, v_{2}, \cdots, v_{n}\right)$. Then, according to experts' responses, the score assessment matrix of the entire index system $(R)$ can be acquired, which is denoted as follows:

$$
R=\left(r_{i j}\right)_{m \times n}=\left[\begin{array}{cccc}
r_{11} & r_{12} & \ldots & r_{1 n} \\
r_{21} & r_{22} & \ldots & r_{2 n} \\
\cdot & \cdot & \cdot & \cdot \\
r_{m 1} & r_{m 2} & \ldots & r_{m n}
\end{array}\right]
$$

where $n$ is the number of the decision schemes; $m$ is the number of indicators of index system; $R_{i}=\left(r_{i 1}, r_{i 2}, r_{i 3}, \cdots, r_{i m}\right),(i=1,2,3, \cdots, m)$ is the single index fuzzy assessment class of index $\mathrm{i}$; and $r_{i j}$ is the membership degree. 
The assessment score matrix $(R)$ and the global weight of each attribute $(W)$ obtained from Steps 4 and 5 are multiplied to get fuzzy evaluation results of the index system. The result of fuzzy comprehensive assessment of multiple indices is as follows:

$$
Z=W \cdot R=\left\{Z_{1}, Z_{2}, \ldots, Z_{n}\right\}=\left\{w_{1}, w_{2}, \ldots, w_{m}\right\} \cdot\left[\begin{array}{cccc}
r_{11} & r_{12} & \ldots & r_{1 n} \\
r_{21} & r_{22} & \ldots & r_{2 n} \\
\cdot & \cdot & \cdot & \cdot \\
r_{m 1} & r_{m 2} & \ldots & r_{m n}
\end{array}\right]
$$

where $Z_{i}$ is the final score of the $i$ th plan after fuzzy comprehensive assessment. The decision scheme with the largest $Z_{i}$ is the optimal plan.

\section{Framework for Social Performance Evaluation of Hospital Redevelopment Project}

To develop a systematic framework to evaluate social performance of construction projects, prior studies on social impacts associated with construction projects and requirements for social sustainability indicators for social performance evaluation are beneficial. Besides, to help the understandings of the proposed indicators, a hospital redevelopment project named "South New-Town hospital (Nan Bu Xin Cheng (NBXC) hospital in Chinese)", which locates in the southern part of Nanjing, the capital city of Jiangsu province, China, was introduced in this research as a complement to understand the social performance. The real-world project also helped to conduct the empirical study of the proposed FAHP-based evaluation approach. Social performance of two schemes proposed for the hospital redevelopment project were presented and evaluated using the proposed approach. Figure 2 presents the location and sketch of NBXC hospital projects.

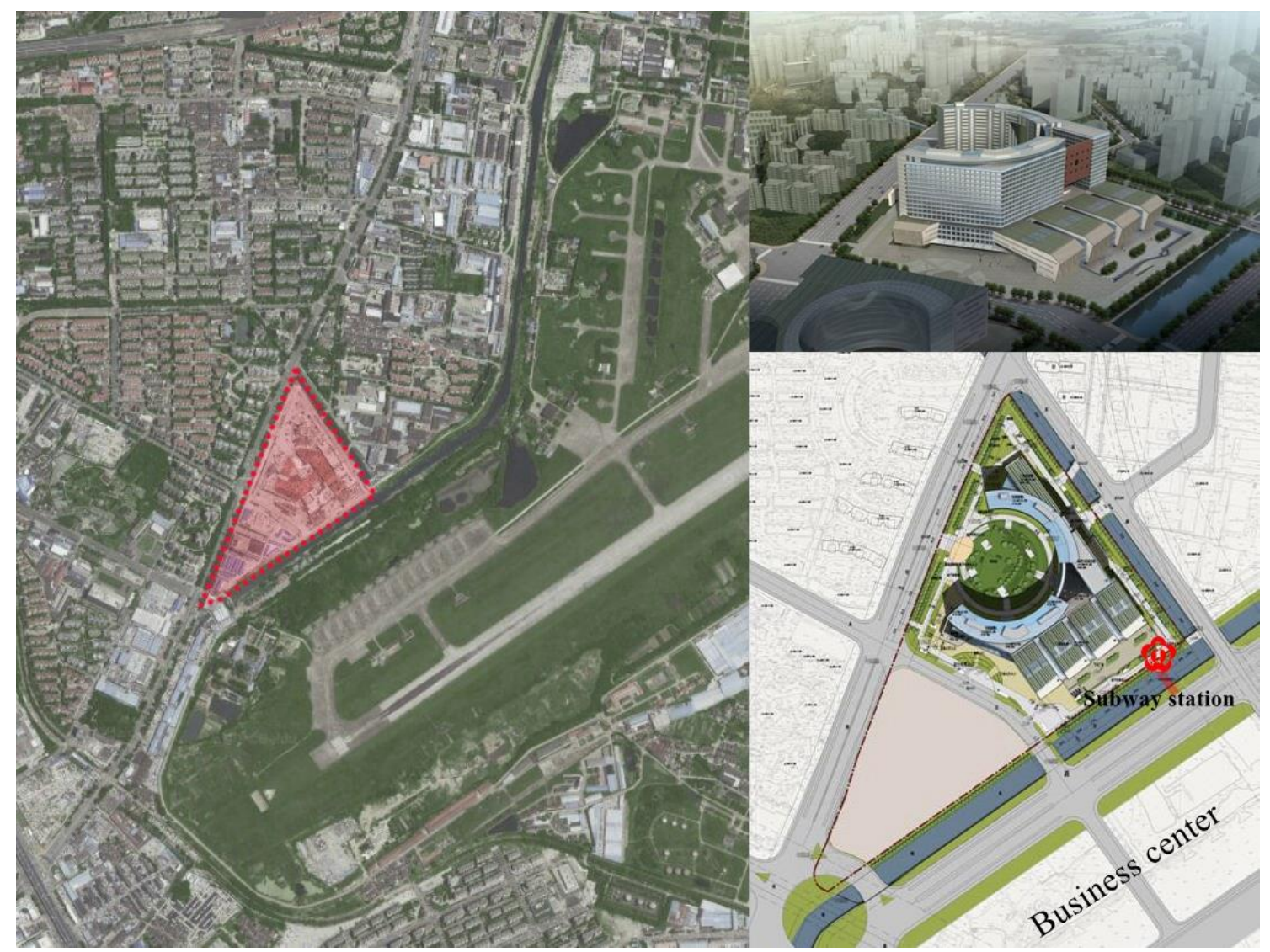

Figure 2. Location and sketch of NBXC hospital project. 


\subsection{Social Impacts of the Hospital Redevelopment Project}

Before NBXC hospital project was developed, a community hospital, which only had basic equipment and provided only outpatient service to the nearby residents, had run for years. However, the rapid urbanization accompanied with fast increase in aging population have led to great challenges to the capacity and service of hospitals [47]. As the community hospital could only provide basic medical service, it could no longer satisfy the demands of the nearby communities due to its outdated equipment and capacity. As shown in the left part of Figure 2, a military airport and several residential communities are around the former hospital. Therefore, this area was quite noisy due to the takeoff and landing of aircraft. In addition, the development of transportation system as well as the local economy were highly restricted by the military zone.

In 2010, the local government decided to redevelop the hospital and two schemes were proposed. The first scheme (Scheme 1) was to redevelop the hospital without demolishing it and just replace the outdated equipment with the latest one. This scheme would not change the land use of nearby area and thereby make little disturbance to the nearby communities. Accordingly, it would require little investment and improve the capacity of the hospital, which is seriously concerned by the local government when the populations are gradually increasing with the rapid urbanization of Nanjing. The second scheme (Scheme 2) suggested building the NBXC hospital project. The former building for the community hospital would be demolished in Scheme 2 to build the NBXC hospital project. Medical experts and advanced medical equipment would be introduced in the new hospital. Finally, Scheme 2 was selected and NBXC hospital project started from January 2012 and would begin operation in June 2018. Table 3 briefly compares the parameters of Schemes 1 and 2.

Table 3. A brief comparison of Schemes 1 and 2.

\begin{tabular}{ccc}
\hline Parameter & Scheme 1 & Scheme 2 \\
\hline Investment & Less than 1 million CNY & 3.5 billion CNY \\
Capacity & No bed available & 1500-bed \\
Service & Outpatient service only & Outpatient and inpatient service \\
Floor area & Less than 1000 square meter & Over 300,000 square meter \\
Other function & No other function & Research and development \\
Nearby facilities & Military airport & Subway station, business centers \\
Service area & Local community & National \\
\hline
\end{tabular}

To build NBXC hospital, the government negotiated with the military sector and changed the land use; the airport was relocated to another area of the city. The affected residents were resettled and compensations were also paid. As presented in Figure 2 and Table 3, the government invested 3.5 billion $\mathrm{CNY}$ on this project with an ambitious plan to improve the nearby circumstance. Finally, NBXC hospital covers an area of over six acres, which consists of several buildings providing inpatient, outpatient, and emergency healthcare services; buildings for research purpose; etc. The main building is a nineteen-story building with two stories underground, and a total floorage of $>300,000 \mathrm{~m}^{2}$, which could provide 1500-bed capacity for the public. One subway line and several municipal roads were built to make it easier for the public to get to the hospital. In addition, the newly built NBXC hospital was equipped with the latest technologies, and special considerations were also given to the medical waste management to avoid polluting the local environment. As declared by the government, NBXC hospital ranks among the first tier nationwide according to the Chinese medical ranking system. The operation of NBXC hospital would greatly help to enhance healthcare service of this area and satisfy the demands of the local residents for high quality healthcare service. In addition, with the advanced technologies and most famous experts, NBXC is also attractive for patients of all the country, which would drive the development of local economy. 


\subsection{Framework for Social Performance Evaluation of Hospital Redevelopment Project}

Based on the extensive literature review and the case of the major hospital projects, 18 indicators were proposed for the social performance evaluation of the hospital redevelopment project and these indicators could be categorized into five dimensions (i.e., socio-economy development, socio-environment development, social flexibility, public service development, and environment and resource conservation). Eighteen indicators within five dimensions are presented in Table 4.

The first dimension shows that the development of the hospital redevelopment project may enhance the socio-economy. As stated by Shen, et al. [2], the development of construction projects would provide local employment opportunities and regional economic development. The development of a certain type of construction project, e.g., the hospital project, could change the industrial structure of the local economy. In addition, the development of construction projects may change the land use [48]. In this case, to develop the hospital project, the local government changed the land use by relocating the military airport and resettling some nearby residents.

The second dimension indicates that the hospital redevelopment project would change the socio-environment. The development of construction projects would help to deliver more infrastructure and enhance the service to the public [49]. Therefore, it would improve their living standard and the level of social security. As described in the case, the development of the NBXC hospital project changed the situation that people living near the military airport had to endure the noisy warplanes. Instead, people could receive high level of healthcare service. Major projects such as hospitals would be landmarks of the city and improve the regional reputation.

The third dimension indicates that the social performance of construction projects would be influenced by social flexibility of the construction projects, which is the adaptabilities of projects to the society (e.g., government, investor, end-users, etc.). The development of construction projects is to satisfy the appeals of diverse stakeholders within the lifecycle of projects [26] and meet the compliance with the policies (e.g., safety and health regulations). Specifically, the hospital project should give special considerations for the patients.

The fourth dimension is the public service offered by the hospital redevelopment project. Different types of construction projects may enhance specific public services by the development of specific infrastructure. For example, the development of transportation infrastructure would provide a faster, more convenient and economical means of transportation method for the citizens [50]. In the hospital project, NBXC hospital would improve the regional capacity of healthcare and disease prevention, promote the advancement of medical technologies and education, and enhance the ability of response to emergency healthcare service.

The last dimension is the influences of the hospital redevelopment project on environment and resource conservation. Most construction projects have great impacts on the landscape of the city. In most cases, the newly built projects are national, regional, or local landmarks. Therefore, it would help to prompt the image of cities. Construction activities and operation of the infrastructure would consume nature resource and generate waste, which may contaminate the environment [20]. In hospital projects, medical waste and disposals generated in the operation stage may spread viruses and threat the health of the public, which should be carefully dealt with [51]. 
Table 4. Framework for social performance evaluation of hospital redevelopment projects.

\begin{tabular}{cccc}
\hline Target Layer & Dimensions & Indicators & Source \\
\hline & Socio-economy & $C_{11}$ Employment rate & {$[2,50]$} \\
& development & $C_{12}$ Regional economic development & {$[14,27,50]$} \\
& $B_{1}$ & $C_{13}$ Industrial structure & {$[2,50]$} \\
& Socio-environment & $C_{14}$ Land use & {$[7,48]$} \\
\cline { 2 - 4 } & development & $C_{22}$ Resident's living standard & {$[8,27]$} \\
Indicators for social & $B_{2}$ & $C_{23}$ Social security & {$[50]$} \\
performance evaluation & $C_{24}$ Regional reputation & {$[2]$} \\
of the hospital & Social flexibility & $C_{31}$ Stakeholders satisfaction & {$[9,19]$} \\
redevelopment & $B_{3}$ & $C_{32}$ Compliance with policies & {$[5,50]$} \\
projects A & $C_{33}$ Patients satisfaction & {$[40]$} \\
& Public service & $C_{41}$ Healthcare and disease prevention & Cases \\
\cline { 2 - 4 } & development & $C_{42}$ Development of medical technologies & Cases \\
& $B_{4}$ & and education & Cases \\
& $C_{43}$ Emergency healthcare service ability & Cases \\
\cline { 2 - 4 } & Environment and & $C_{51}$ Landscape of the city & {$[48]$} \\
& resource & $C_{52}$ Wastage management & {$[2,20]$} \\
& conservation & $C_{53}$ Resource depletion & {$[2,21,27]$} \\
& $B_{5}$ & $C_{54}$ Environmental protection & {$[14,27,52]$} \\
\hline
\end{tabular}

\section{An Empirical Study}

To help evaluate the social performance of hospital projects, ten domain experts were investigated separately to contribute their expertise in this research. The criteria for the selection of experts are working experience and background. These experts should have over ten years of working experience in their working fields, which ensures that the investigated experts have a good knowledge of social impacts associated with the project. The expert team consisted of three from different department of local government, who are responsible for the development of this area; three from research institutions, who are familiar with construction project management and social sustainability; two from the contractor of NBXC hospital projects; and two representatives (i.e., one doctor and one nurse) of the NBXC hospital staff. These experts were visited individually and face-to-face investigations were conducted at their office to ensure the independence of this research. Research background and research approach were introduced to these experts to help them get a quick and comprehensive understandings about the project and this research, which would further ensure the quality of this research. After the introduction, the experts were first required to give remarks on the weight of social performance indicators based on their expertise.

Fuzzy numbers given by the experts determined relative importance of one index over the other, which further helped to build a fuzzy judgment vector. The judgment vectors help to form portions of the fuzzy pairwise comparison matrix, which is then adopted to determine the weight of each criterion. The result of consistency check indicates the objectiveness of the weight of each criterion. Meanwhile, the total sequencing weight sets of social performance assessment index system $(W)$ is built, as shown in Table 5.

To quantify the magnitude of hospital redevelopment project affecting each social performance indicator, the semantic scales of each subjective assessment index was quantified and the assessment class $V=\left(v_{1}, v_{2}, \cdots, v_{n}\right)$ was further classified into fivescales (i.e., high, relatively higher, average, relatively lower, and low), as shown in Table 6. As suggested by Table 6, the standard values of social performance evaluation should be over 0.6 , which indicates that the construction projects are contributory to the social sustainability. 
Table 5. The weight for each indicator in social performance evaluation system.

\begin{tabular}{|c|c|c|c|c|c|c|}
\hline \multirow{2}{*}{$A$} & $B_{1}$ & $B_{2}$ & $B_{3}$ & $B_{4}$ & $B_{5}$ & \multirow{2}{*}{ Weight } \\
\hline & 0.442 & 0.252 & 0.063 & 0.129 & 0.114 & \\
\hline$C_{11}$ & 0.182 & & & & & 0.080 \\
\hline$C_{12}$ & 0.512 & & & & & 0.226 \\
\hline$C_{13}$ & 0.084 & & & & & 0.037 \\
\hline$C_{14}$ & 0.223 & & & & & 0.099 \\
\hline$C_{21}$ & & 0.533 & & & & 0.134 \\
\hline$C_{22}$ & & 0.237 & & & & 0.060 \\
\hline$C_{23}$ & & 0.140 & & & & 0.035 \\
\hline$C_{24}$ & & 0.098 & & & & 0.025 \\
\hline$C_{31}$ & & & 0.406 & & & 0.026 \\
\hline$C_{32}$ & & & 0.322 & & & 0.020 \\
\hline$C_{33}$ & & & 0.271 & & & 0.017 \\
\hline$C_{41}$ & & & & 0.209 & & 0.027 \\
\hline$C_{42}$ & & & & 0.391 & & 0.050 \\
\hline$C_{43}$ & & & & 0.401 & & 0.052 \\
\hline$C_{51}$ & & & & & 0.134 & 0.015 \\
\hline$C_{52}$ & & & & & 0.383 & 0.044 \\
\hline$C_{53}$ & & & & & 0.197 & 0.022 \\
\hline$C_{54}$ & & & & & 0.286 & 0.033 \\
\hline
\end{tabular}

Table 6. Weighted and standard values of the magnitude of construction redevelopment project.

\begin{tabular}{cccccc}
\hline Influential Degree & High & Relatively High & Average & Relatively Low & Low \\
\hline Weighted Values & 1.0 & 0.8 & 0.5 & 0.2 & 0 \\
Standard Values & $0.900 \sim 1.0$ & $0.6 \sim 0.899$ & $0.4 \sim 0.599$ & $0.2 \sim 0.399$ & $0 \sim 0.2$ \\
\hline
\end{tabular}

Notes: (1) Influential degree of social performance can vary according to the need of actual classifications, which is generally divided into five scales; and (2) weighted values and standard values are all determined according to experiences.

To provide a comprehensive view about social performance of the hospital redevelopment project, a comparative analysis of Schemes 1 and 2 is presented in this paper. Ten invited experts were asked to score the social performance indices of Schemes 1 and 2 based on Table 4 . The mean values of these indicators in both scheme were calculated and the membership degree of 18 two-level indices was obtained, as shown in Table 7.

Table 7. Membership degree of social performance evaluation of both scheme.

\begin{tabular}{cccccc}
\hline \multirow{2}{*}{ Indicator } & \multicolumn{2}{c}{ Membership Degree } & & \multicolumn{2}{c}{ Membership Degree } \\
\cline { 2 - 3 } & Scheme 2 & Scheme 1 & & Scheme 2 & Scheme 1 \\
\hline$C_{11}$ & 0.911 & 0.256 & $C_{32}$ & 0.867 & 0.156 \\
$C_{12}$ & 0.722 & 0.244 & $C_{33}$ & 0.756 & 0.111 \\
$C_{13}$ & 0.600 & 0.156 & $C_{41}$ & 0.433 & 0.533 \\
$C_{14}$ & 0.533 & 0.300 & $C_{42}$ & 0.778 & 0.211 \\
$C_{21}$ & 0.756 & 0.211 & $C_{43}$ & 0.633 & 0.278 \\
$C_{22}$ & 0.689 & 0.244 & $C_{51}$ & 0.467 & 0.300 \\
$C_{23}$ & 0.533 & 0.244 & $C_{52}$ & 0.622 & 0.722 \\
$C_{24}$ & 0.567 & 0.089 & $C_{53}$ & 0.466 & 0.567 \\
$C_{31}$ & 0.911 & 0.022 & $C_{54}$ & 0.700 & 0.811 \\
\hline
\end{tabular}


The synthetized evaluation matrix (R) of both scheme could be developed according to Table 7 . By taking the advantage of Table 3, total sequencing weight sets of social performance $(W)$ can be obtained. Therefore, social performance of each scheme could be obtained as below.

$$
\left.Z=W \cdot R=\left[\begin{array}{l}
0.080 \\
0.226 \\
0.037 \\
0.099 \\
0.134 \\
0.060 \\
0.035 \\
0.025 \\
0.026 \\
0.020 \\
0.017 \\
0.027 \\
0.050 \\
0.052 \\
0.015 \\
0.044 \\
0.022 \\
0.033
\end{array}\right]^{T}\right]^{T}\left[\begin{array}{ll}
0.911 & 0.256 \\
0.722 & 0.244 \\
0.600 & 0.156 \\
0.533 & 0.300 \\
0.756 & 0.211 \\
0.689 & 0.244 \\
0.533 & 0.244 \\
0.567 & 0.089 \\
0.911 & 0.022 \\
0.867 & 0.156 \\
0.756 & 0.111 \\
0.433 & 0.533 \\
0.778 & 0.211 \\
0.633 & 0.278 \\
0.467 & 0.300 \\
0.622 & 0.722 \\
0.466 & 0.567 \\
0.700 & 0.811
\end{array}\right]=[0.692,0.285]
$$

The social performance of Schemes 2 and 1 are 0.692 and 0.285 , respectively, which shows social performance of the hospital redevelopment project of Scheme 2 is much higher than that of Scheme 1. In addition, the result of Scheme $2(0.692)$ is relatively high according to membership degree given by Table 6. It also suggests that the construction of NBXC project (Scheme 2) is a successful project from the perspective of social aspect and would contribute to the social sustainability of the society.

\section{Discussion}

This research proposed 18 indicators for social performance evaluation of the hospital redevelopment project from five dimensions. Ten experts were asked to contribute their expertise to evaluate the social performance of two proposed schemes based on FAHP method. The result of comparative analysis shows the development of NBXC hospital project has a relative high social performance and it would contribute to project success and social sustainability. A modified K-chart was employed to help the discussion of research results. In Figure 3, the shaded rectangle shows the indicators are positively associated with development of NBXC hospital project, where social performance of Scheme 2 is higher than that of Scheme 1, while the white rectangle indicates the negative relationship between indicators and development of NBXC hospital project, where social performance of Scheme 1 is higher than Scheme 2.

As shown in Figure 3, social performance of NBXC hospital project is positively reflected by socio-economy development, socio-environment development and social flexibility, as well as the development of public service. The increase of employment rate $\left(C_{11}\right)$ and satisfaction of stakeholders $\left(C_{31}\right)$ rank at the top among all indicators. The development of NBXC hospital helps to deliver more infrastructure (i.e., hospital, transportation infrastructure, etc.) and enhance the public service $\left(C_{22}\right)$ which would create more job opportunities and meet the demands of diverse stakeholders, for example, the patients $\left(C_{33}\right)$ as end-users are also satisfied by the development of NBXC hospital projects. To develop this project, the military airport and nearby resident communities were relocated. Local government made a sound plan for the land use $\left(C_{13}\right)$, e.g., business center and subway station were built nearby NBXC hospital, which helps to increase the value of the nearby land and 
redevelopment the landscape of the city $\left(C_{51}\right)$, and further stimulate regional economic development $\left(C_{12}\right)$, adjust the industrial structure $\left(C_{14}\right)$, and improve the living standard of the local residents $\left(C_{21}\right)$. The newly built hospital also encourages research and development (R\&D) in medical technologies and education $\left(C_{42}\right)$. Medical service provided by NBXC hospital project would enhance social security $\left(C_{23}\right)$ and improve emergency healthcare service ability $\left(C_{43}\right)$ of this region. However, NBXC hospital as the first tier hospital in China would attract patients of other regions of the country, which may lead to risks of exposure to diverse disease and challenge healthcare and disease prevention $\left(C_{41}\right)$.

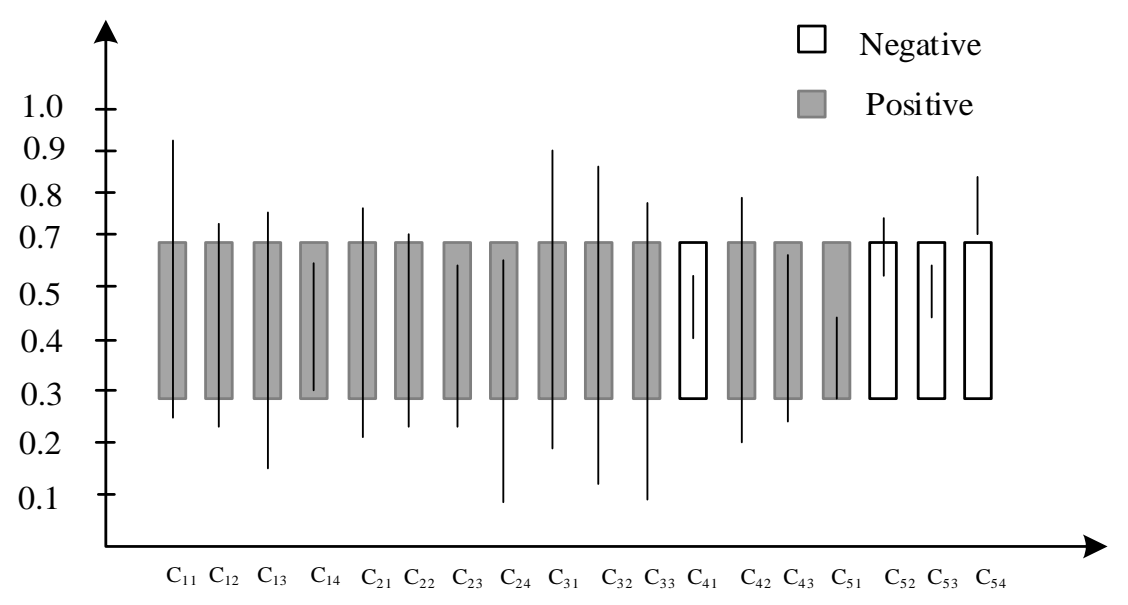

Figure 3. A modified K-chart of the research results.

The development of NBXC hospital project would negatively influence the society from the dimension of environment and resource conservation. The lifecycle of NBXC hospital project would consume enormous resource $\left(C_{53}\right)$, and generate waste $\left(C_{52}\right)$ (e.g., construction waste and medical waste), which would bring burden to the environment $\left(C_{53}\right)$.

The scores of social performance evaluation of two proposed schemes show Scheme 2 would bring more social wellbeing to the society than Scheme 1 for the hospital redevelopment project. The score of social performance evaluation using Scheme 2 is 0.692 , which also indicates relative high social performance of NBXC hospital project. Therefore, NBXC hospital project could be claimed to be a successful project from the social perspective and it will contribute to the sustainability of the society.

\section{Conclusions}

The concept of sustainable development suggests interactions of economic, environmental, and social dimensions [2]. However, social sustainability has received less appreciation than economic and environmental dimensions [28]. In the construction industry, social performance of construction projects not only contributes to social sustainability but also is critical for project success [19]. Evaluation of social performance of construction projects would help decision makers when proposing a project and project managers continuously improve social performance of construction projects.

This study developed a systematic framework for social performance evaluation of construction projects with 18 indicators developed from previous studies and a real-world hospital redevelopment project. These indicators help to evaluate social performance of the hospital redevelopment projects from five dimensions: socio-economy development, socio-environment development, social flexibility, public service development, and environment and resource conservation. In this research, public service delivered by hospital may vary from other types of infrastructure, e.g., schools and subways. However, the proposed framework could also be employed as reference to evaluate social performance of construction projects. While social impacts are intangible, and prior social performance evaluation using indicators are time-consuming and relatively subjective [13], FAHP method was introduced 
in this research to improve the efficiency and reduce the objectivity of the evaluation process to a certain degree.

The empirical study helps to showcase the processes to evaluate social performance of construction projects using the proposed framework and FAHP-based method. More importantly, the empirical study also helps to demonstrate how to improve social performance of construction projects based on the evaluation results. Specifically, the development of NBXC hospital project would improve the social sustainability of the society from perspectives of socio-economy development, socio-environment development, and social flexibility. Meanwhile, the development of NBXC hospital could also improve the landscape of the city due to a sound plan. However, the environment and resource conservation may be negatively impacted by NBXC hospital. As a hospital project, special considerations should be given to the associated risks of healthcare and disease prevention. By improving waste management, reducing resource depletion, and enhancing environmental protection, social performance of NBXC hospital project could be further improved.

However, this research was also subject to some limitations. For example, as stated by Vanclay [13], social impacts of construction projects are strongly correlated to the project context, while indicators for social performance evaluation are strongly dependent on the characteristics of construction projects. Therefore, future research should extend the flexibility and ensure the validity of the proposed framework.

Author Contributions: The author X.X., Y.T., and J.Y. drafted the manuscript, X.X., J.Y., and Q.L. designed the framework and research methodology. X.X. and Y.T. assisted in data collection and data analysis. T.C. and P.L. helped to polish the language. All authors have read and approved the final version of the manuscript.

Funding: The authors wish to give their sincere gratitude to the National Natural Science Foundation of China (grant Nos. 51578144, 71472037, and 71671042); the Postgraduates' Science and Innovation Foundation of Jiangsu Province(grant No. KYLX_0206); and Priority Academic Program Development of Jiangsu Higher Education Institutions. The Program for Outstanding Young Teachers of Southeast University (2242015R30009) and the Fundamental Research Funds for the Central Universities are acknowledged for financially supporting this research.

Acknowledgments: The authors also express their gratitude to experts who participated in this research and provided their expertise, as well as the anonymous reviewers, who provided constructive suggestions for the authors to improve their research and modified this paper.

Conflicts of Interest: The authors declare no conflict of interest.

\section{References}

1. Sev, A. How can the construction industry contribute to sustainable development? A conceptual framework. Sustain. Dev. 2009, 17, 161-173. [CrossRef]

2. Shen, L.Y.; Hao, J.L.; Tam, V.W.Y.; Yao, H. A checklist for assessing sustainability performance of construction projects. J. Civ. Eng. Manag. 2007, 13, 273-281.

3. Taroun, A. Towards a better modelling and assessment of construction risk: Insights from a literature review. Int. J. Proj. Manag. 2014, 32, 101-115. [CrossRef]

4. Vifell, Å.C.; Soneryd, L. Organizing matters: How 'the social dimension'gets lost in sustainability projects. Sustain. Dev. 2012, 20, 18-27. [CrossRef]

5. Wang, Y.; Han, Q.; de Vries, B.; Zuo, J. How the public reacts to social impacts in construction projects? A structural equation modeling study. Int. J. Proj. Manag. 2016, 34, 1433-1448. [CrossRef]

6. Vanclay, F. Principles for social impact assessment: A critical comparison between the international and US documents. Environ. Impact Assess. Rev. 2006, 26, 3-14. [CrossRef]

7. Tilt, B.; Braun, Y.; He, D. Social impacts of large dam projects: A comparison of international case studies and implications for best practice. J. Environ. Manag. 2009, 90, S249-S257. [CrossRef] [PubMed]

8. Li, D.; Chen, H.; Hui, E.C.M.; Yang, H.; Li, Q. A methodology for ex-post assessment of social impacts of an affordable housing project. Habitat Int. 2014, 43, 32-40. [CrossRef]

9. Shi, Q.; Liu, Y.; Zuo, J.; Pan, N.; Ma, G. On the management of social risks of hydraulic infrastructure projects in China: A case study. Int. J. Proj. Manag. 2015, 33, 483-496. [CrossRef]

10. Becker, H.A. Social impact assessment. Eur. J. Oper. Res. 2001, 128, 311-321. [CrossRef] 
11. Ahmadvand, M.; Karami, E. A social impact assessment of the floodwater spreading project on the Gareh-Bygone plain in Iran: A causal comparative approach. Environ. Impact Assess. Rev. 2009, 29, 126-136. [CrossRef]

12. IAIA, International Association for Impact Assessment. Available online: http://www.iaia.org (accessed on 28 June 2018).

13. Vanclay, F. Conceptualising social impacts. Environ. Impact Assess. Rev. 2002, 22, 183-211. [CrossRef]

14. Valdes-Vasquez, R.; Klotz, L.E. Social sustainability considerations during planning and design: Framework of processes for construction projects. J. Constr. Eng. Manag. 2012, 139, 80-89. [CrossRef]

15. Strand, R. A systems paradigm of organizational adaptations to the social environment. Acad. Manag. Rev. 1983, 8, 90-96. [CrossRef]

16. Wartick, S.L.; Cochran, P.L. The evolution of the corporate social performance model. Acad. Manag. Rev. 1985, 10, 758-769. [CrossRef]

17. Salazar, J.; Husted, B.W.; Biehl, M. Thoughts on the evaluation of corporate social performance through projects. J. Bus. Ethics 2012, 105, 175-186. [CrossRef]

18. Herd-Smith, A.; Fewings, P. The Implementation of Social Sustainability in Regeneration Projects: Myth or Reality? Royal Institution of Chartered Surveyors (RICS): London, UK, 2008; Available online: http:/ /www.rics.org/ site/scripts/download_info.aspx (accessed on 28 June 2018).

19. Liu, B.; Li, Y.; Xue, B.; Li, Q.; Zou, P.X.; Li, L. Why do individuals engage in collective actions against major construction projects?-An empirical analysis based on Chinese data. Int. J. Proj. Manag. 2018, 36, 612-626. [CrossRef]

20. Yuan, H. A model for evaluating the social performance of construction waste management. Waste Manag. 2012, 32, 1218-1228. [CrossRef] [PubMed]

21. Shen, L.-Y.; Tam, V.W.; Tam, L.; Ji, Y.-B. Project feasibility study: The key to successful implementation of sustainable and socially responsible construction management practice. J. Clean. Prod. 2010, 18, 254-259. [CrossRef]

22. Bassioni, H.A.; Price, A.D.; Hassan, T.M. Building a conceptual framework for measuring business performance in construction: An empirical evaluation. Constr. Manag. Econ. 2005, 23, 495-507. [CrossRef]

23. Tam, V.W.; Tam, C.; Zeng, S.; Chan, K. Environmental performance measurement indicators in construction. Build. Environ. 2006, 41, 164-173. [CrossRef]

24. Kagioglou, M.; Cooper, R.; Aouad, G. Performance management in construction: A conceptual framework. Constr. Manag. Econ. 2001, 19, 85-95. [CrossRef]

25. Ullmann, A.A. Data in search of a theory: A critical examination of the relationships among social performance, social disclosure, and economic performance of US firms. Acad. Manag. Rev. 1985, 10, 540-557.

26. Trop, T. Social Impact Assessment of Rebuilding an Urban Neighborhood: A Case Study of a Demolition and Reconstruction Project in Petah Tikva, Israel. Sustainability 2017, 9, 1076. [CrossRef]

27. Zuo, J.; Jin, X.-H.; Flynn, L. Social sustainability in construction-an explorative study. Int. J. Constr. Manag. 2012, 12, 51-63. [CrossRef]

28. Almahmoud, E.; Doloi, H.K. Assessment of social sustainability in construction projects using social network analysis. Facilities 2015, 33, 152-176. [CrossRef]

29. Liu, Z.-Z.; Zhu, Z.-W.; Wang, H.-J.; Huang, J. Handling social risks in government-driven mega project: An empirical case study from West China. Int. J. Proj. Manag. 2016, 34, 202-218. [CrossRef]

30. Bititci, U.S.; Carrie, A.S.; McDevitt, L. Integrated performance measurement systems: A development guide. Int. J. Oper. Prod. Manag. 1997, 17, 522-534. [CrossRef]

31. Bassioni, H.A.; Price, A.D.; Hassan, T.M. Performance measurement in construction. J. Manag. Eng. 2004, 20, 42-50. [CrossRef]

32. Yang, H.; Yeung, J.F.; Chan, A.P.; Chiang, Y.; Chan, D.W. A critical review of performance measurement in construction. J. Facil. Manag. 2010, 8, 269-284. [CrossRef]

33. Lewis, J. The Project Manager's Desk Reference: A Comprehensive Guide to Project Planning, Scheduling, Evaluation, and System; McGraw-Hill: New York, NY, USA, 2000.

34. Lin, G.; Shen, Q. Measuring the performance of value management studies in construction: Critical review. J. Manag. Eng. 2007, 23, 2-9. [CrossRef]

35. Walker, A. Project Management in Construction; John Wiley \& Sons: Chichester, UK, 2015. 
36. Dixon, M. The Association for Project Management (APM) Body of Knowledge (BoK); Association for Project Management: High Wycombe, UK, 2000.

37. Nitithamyong, P.; Skibniewski, M.J. Success/failure factors and performance measures of web-based construction project management systems: Professionals' viewpoint. J. Constr. Eng. Manag. 2006, 132, 80-87. [CrossRef]

38. Flyvbjerg, B.; Bruzelius, N.; Rothengatter, W. Megaprojects and Risk: An Anatomy of Ambition; Cambridge University Press: Cambridge, UK, 2003.

39. Atkinson, R. Project management: Cost, time and quality, two best guesses and a phenomenon, its time to accept other success criteria. Int. J. Proj. Manag. 1999, 17, 337-342. [CrossRef]

40. Hinze, J.; Thurman, S.; Wehle, A. Leading indicators of construction safety performance. Saf. Sci. 2013, 51, 23-28. [CrossRef]

41. Suárez, E.; Calvo-Mora, A.; Roldán, J.L.; Periáñez-Cristóbal, R. Quantitative research on the EFQM excellence model: A systematic literature review (1991-2015). Eur. Res. Manag. Bus. Econ. 2017, 23, 147-156. [CrossRef]

42. Chan, A.P.; Chan, A.P. Key performance indicators for measuring construction success. Benchmarking Int. J. 2004, 11, 203-221. [CrossRef]

43. Saaty, T.L. Decision Making for Leaders: The Analytical Hierarchy Process for Decisions in a Complex Work; Lifetime Learning Publications: Maastricht, The Netherlands, 1981.

44. Zeng, J.; An, M.; Smith, N.J. Application of a fuzzy based decision making methodology to construction project risk assessment. Int. J. Proj. Manag. 2007, 25, 589-600. [CrossRef]

45. Haider, S.; Ahmad, J.; Ahmed, M. Identifying barriers to implementation of health promoting schools in Pakistan: The use of qualitative content analysis and fuzzy analytic hierarchy process. Int. J. Adv. Appl. Sci. 2018, 5, 56-66. [CrossRef]

46. Csutora, R.; Buckley, J.J. Fuzzy hierarchical analysis: The Lambda-Max method. Fuzzy Sets Syst. 2001, 120, 181-195. [CrossRef]

47. Lutz, W.; Sanderson, W.; Scherbov, S. The coming acceleration of global population ageing. Nature 2008, 451, 716. [CrossRef] [PubMed]

48. Calvo, F.; de Oña, J.; Arán, F. Impact of the Madrid subway on population settlement and land use. Land Use Policy 2013, 31, 627-639. [CrossRef]

49. Chang, Z.; Phang, S.-Y. Urban rail transit PPPs: Lessons from East Asian cities. Transp. Res. Part A: Policy Pract. 2017, 105, 106-122. [CrossRef]

50. Yuan, J.F.; Skibniewski, M.J.; Li, Q.; Shan, J. The driving factors of china's public-private partnership projects in Metropolitian transportation systems: Public sector's viewpoint. J. Civ. Eng. Manag. 2010, 16, 5-18. [CrossRef]

51. Mantzaras, G.; Voudrias, E.A. An optimization model for collection, haul, transfer, treatment and disposal of infectious medical waste: Application to a Greek region. Waste Manag. 2017, 69, 518-534. [CrossRef] [PubMed]

52. Momtaz, S.; Kabir, S.Z. Evaluating Environmental and Social Impact Assessment in Developing Countries; Elsevier: Waltham, MA, USA, 2013.

(C) 2018 by the authors. Licensee MDPI, Basel, Switzerland. This article is an open access article distributed under the terms and conditions of the Creative Commons Attribution (CC BY) license (http:/ / creativecommons.org/licenses/by/4.0/). 